\title{
Entre el riesgo y la emergencia: insinuaciones policiales en la intervención social
}

\section{Between risk and emergency: The increasing police approach in social interventions strategies}

\author{
Débora ÁVILA CANTOS \\ Universidad de Castilla la Mancha \\ debora.avila@uclm.es \\ Sergio GARCÍA GARCÍA \\ Universidad Complutense de Madrid \\ apropiacionindebida@gmail.com
}

Recibido: 3 de marzo de 2013

Aceptado: 2 de julio de 2013

\begin{abstract}
Resumen
Las crisis, como todo torbellino, tambalean, cuando no arrasan, buena parte de lo que queda bajo su campo de acción. Pocas dudas quedan ya de que aquello que en un principio parecía exclusivo del campo económico-financiero, se manifiesta también en términos políticos y sociales. Son muchas las voces que alertan del fin de un modelo social, ese que definió el desarrollo del Estado del Bienestar tal cual lo conocemos, ahogado entre las oleadas de recortes, externalizaciones, privatizaciones, cierres, despidos, rescates... Sin embargo, el fin de un modelo no conduce al vacío. Que determinadas políticas sociales se desvanezcan no significa que otras no irrumpan con fuerza. De hecho, la crisis no hace sino expresar en términos máximos una transformación que hacía años venía gestándose: el surgir de una política social específicamente neoliberal que, tomando para sí muchas de las propias estructuras del Estado del Bienestar, introduce en ellas nuevas lógicas de gobierno y gestión de lo social.

En el presente artículo, resultado del diálogo entre los trabajos de los arriba firmantes, intentaremos desentrañar lo que, a nuestro juicio, constituye una de las principales transformaciones experimentadas por las políticas sociales en su devenir neoliberal: el desplazamiento hacia un abordaje cada vez más policial de la gestión de las poblaciones. Un desplazamiento que, en realidad, es doble, pues implica un movimiento que estetiza, por un lado, a la policía para acercarla en sus formas a los profesionales de la intervención social mientras que, por otro, introduce en estos últimos lógicas más propias de la actuación policial. Un desplazamiento que, en definitiva, no hace sino responder a las exigencias de las nuevas filosofías de gobierno que acompañan a las políticas sociales neoliberales.
\end{abstract}

Palabras clave: riesgo, emergencia, intervención social, policialización, (in)seguridad. 


\begin{abstract}
Many voices warn us of the eminent end of the social model that shaped the Welfare State as we know it. The disappearance of certain social policies, however, does not mean that others do not appear with great force. In fact, the crisis is none other than the maximum expression of a transformation that has been inching its way forward for years: the appearance of a specifically neoliberal social policy that, while incorporating many elements of the Welfare State, introduces new logic in government and social management.

This article is the result of a dialogue between the works of those whose names appear above. Our intention is to untangle what we consider to be one of the central transformations in social policy on the neoliberal path: the shift towards an ever-increasing police-like approach in the management of the population. This shift (which actually goes two ways as it includes on the one hand, the make-over of police to make them appear more like social work professionals, while at the same time, the introduction of a police-like mindset into the social intervention sector), directly responds to the demands of the new government philosophy that is brought forth by neoliberal social policies.
\end{abstract}

Keywords: neoliberalism, social protection, public safety, risk, emergency.

Referencia normalizada: Ávila Cantos, D. y García García, S. (2013) Entre el riesgo y la emergencia: insinuaciones policiales en la intervención social, en Revista de Antropología Social, 22: 59-82

SUMARIO: 1. Preámbulo: de policías tutores e interventores de urgencias. 2. Título I: de la intervención desde el riesgo. 3. Título II: de las amenazas que emergen. 4. Disposición transitoria primera: de la policialización de lo social. 5. Disposición transitoria segunda: de la (in) seguridad como cemento social. 6. Disposición final. 7. Referencias bibliográficas.

\title{
1. Preámbulo: de policías tutores e interventores de urgencias
}

En la primavera de 2012, asociaciones y profesionales de la intervención social fueron invitados a un encuentro en el que discutir juntos las distintas problemáticas que rodean a "las chavalas y los chavales en riesgo" de un barrio de Madrid, "ya que entre todos es más fácil hacer las cosas", según rezaba la convocatoria. A dicho encuentro, al que estaban también invitados un experto académico y un responsable de la policía local, acudieron cerca de veinte profesionales. A todos les unía una misma preocupación:

¿Quién se encarga de los menores? En las políticas de juventud no ha habido sino retroceso y recortes... En prevención estamos bajo mínimos... (Experto).

Hay muchos menos recursos que antes.... de los que estábamos en la calle ¿Cuántos nos hemos quedado? 4 ó 5 . De los cientos de recursos en la calle no queda nada. Los chavales siguen estando en la calle, pero los servicios se han ido. Las calles están solas para ellos (Trabajadora social). 
Que los recortes en materia de intervención social sean la tónica en los últimos años es un hecho que a casi nadie coge ya por sorpresa. Quizá lo haga un poco más la respuesta que, ante dichos recortes, el agente de policía proponía a educadores y trabajadores de lo social:

Y no es que yo venga aquí a que hagáis de confidentes con la policía, ni mucho menos... Se trata sencillamente de que tracemos unos lazos, unas redes... porque si un chaval es capaz de informaros o de deciros sus miedos, o que lo han captado, o está implicado en un hecho violento, o es víctima, sobre todo víctima, de un hecho violento pues nos podéis informar (...) Decir sencillamente "en la zona tal, me han dicho chicos que trabajan con nosotros, que puede haber un grupo determinado donde están coaccionando". Con esa misma información nos vale para montar cualquier tipo de dispositivo y seguir esa línea de investigación (...). Porque no implica que educadores o trabajadores sociales tengan que hacer de confidentes para la policía, se trata de darnos información útil para que nosotros podamos seguir trabajando (Polícía municipal).

Desde el saber-poder que su puesto en la universidad le confería, el experto apuntalaba esta petición: "Por eso la policía son insustituibles. Algunos [revuelo en la sala], me refiero a la policía de cercanía, a la de proximidad (...), no a la otra". Aquellos policías que "trabajan desde la cercanía y resuelven problemas", debían ser contemplados, cada vez más, como una opción a la que recurrir en tiempos de crisis. Cuando todo se está desmoronando, ellos permanecen en pie:

Ahora, si tengo un problema tengo que llamar a [responsable policial], porque no hay nadie más en la calle, porque todos los servicios sociales se están yendo, con lo cual ahora sí que nos necesitamos más que nunca (Trabajadora social).

Los recortes no dejan otra opción, por más que su acervo vocacional recuerde a estos profesionales que son otra cosa - esas "herramientas que tienen los educadores, su manera de trabajar e intervenir"-. Máxime cuando se trata de lidiar con chavales que ahora son "más violentos", en un contexto en el que la violencia se lee cada vez menos como fruto de la desigualdad social para resignificarse en una especie de nihilismo vital:

Cuando un chico pertenece a un grupo determinado no es que se aísle, vamos a quitarnos en esto los prejuicios... no se aíslan ni todos vienen de familias rotas. Hacen una vida tranquilamente normal..., lo que pasa es que luego están con su grupo y se tiran las horas muertas (Policía).

La mayor parte del auditorio cruzaba miradas cómplices, las de quienes sabían que ésa, y no otra, era la situación que se vivía en las calles. Algunos, los menos, se revolvían en sus asientos - aunque para revolverse, sobra decir, es necesario estar sentado, haber respondido a la invitación-, recelando de tal propuesta: "como educadores debemos tener otros recursos, abordamos la realidad de otra manera". Pero las desconfianzas se diluían poco a poco en unos códigos y un vocabulario que remiten a modos de hacer que se reconocen cercanos: 
En cuanto a la policía hay que verla como una opción, es que no se trata de ver al agente uniformado que entra cual elefante, pensando que vamos a tomar las calles, porque entonces vamos a generar miedo. Entonces de lo que se trata es de establecer canales, canales de comunicación (...) Trabajar en red. Es una utopía, pero lo decimos todo el rato: trabajar en red, trabajar en red. Pero esto no es sólo entre trabajadores sociales, es necesario incorporar a más actores (Policía).

Por más que algunos trabajadores de lo social se repitieran una y otra vez que "la labor de un policía es distinta a la de un educador social... que no somos lo mismo", lo cierto es que la asociación quedaba trazada. Una asociación que no hace sino hablarnos de una de las principales transformaciones experimentadas por las políticas sociales en su devenir neoliberal: el desplazamiento hacia un abordaje cada vez más policial de la gestión de las poblaciones. Esta tendencia, apuntada por diversos investigadores (Wacquant, 2012; Fassin, 2011; Bonelli, 2006), remite a un vínculo cada vez mayor entre las políticas penales y punitivas y los sectores asistenciales o de intervención social en el abordaje de aquellas "categorías poblemáticas de población que residen en las regiones más bajas del espacio social y urbano" (Wacquant, 2010: 23).

La progresiva policialización de lo social tiene su reflejo en ciudades como Madrid, donde se ha apostado decididamente por aumentar los presupuestos destinados a las políticas de "seguridad ciudadana" de manera independiente a la variación, en uno u otro sentido, de las tasas de criminalidad: el reto es "convertir a Madrid en una de las ciudades más seguras de Europa", una consigna repetida por los mandos policiales pese a que Madrid figure en segundo lugar en el ranking de las ciudades europeas más seguras, sólo por detrás de Copenhague según los datos oficiales ( $E l$ Pais, 17/01/2012).

De manera paralela al incremento de lo policial, los servicios sociales para pobres, que nunca dejaron de ser pobres servicios, perviven a modo de esqueleto institucional: edificios, trabajadores públicos y algunos externalizados, sin apenas contenido, sin ayudas, con contadas plazas en dispositivos de atención y con una Renta Mínima de Inserción (RMI) saturada y recortada que no responde al fuerte incremento de la pobreza. Al mismo tiempo, estos servicios profundizan en programas orientados a contener precisamente el riesgo que la "desprotección social" está generando.

Sin ánimo de negar ese desplazamiento —es más, precisamente para afirmarlo-, pensamos que es necesario un análisis mucho más sutil y complejo que supere el tosco enunciado de "más policía para los pobres". Primero, porque no se trata de un viraje radical en las políticas sociales: nunca los trabajadores y educadores sociales fueron agentes de profunda transformación social, por más que la profesión reclame para sí su compromiso por la "activación" social y la mitigación de situaciones de exclusión. No en vano, su desarrollo contemporáneo se encuentra íntimamente ligado, por un lado, a estrategias de contención de la exclusión social y de cooptación del movimiento de base - vecinal y cristiano- desarrolladas en la década de los ochenta (Observatorio Metropolitano, 2007) y, por otro, a un discurso de la " $m o$ dernización que aborda los problemas ligados a la exclusión como fenómenos a gestionar profesionalmente, al margen de una reflexión sobre el funcionamiento del 
sistema social que los genera" (Colectivo Ioé, 1995: 204), y al margen, también, de un cuestionamiento de las condiciones estructurales y las axiomáticas de poder que subyacen a la intervención social y la sobredeterminan (Ávila y Malo, 2010). Segundo, y más importante aún, porque es necesario señalar que ese desplazamiento es, en realidad, doble. La imagen que proponemos no es la de un tablero de ajedrez en el que las figuras negras - de control — se van comiendo a las blancas — de la intervención socio-educativa - sino la de una mutación en la que unas y otras devienen grises y "atacan” en la misma dirección. Así, las figuras policiales mantienen su lógica de actuación pero adaptan sus formas estéticas a las de la intervención social, mientras que el trabajo social mantiene sus formas, pero adapta algunos rasgos de su lógica de trabajo - los ritmos, el origen de la demanda, ciertos principios de intervención - a aquélla que siempre ha sido más propia de la actuación policial.

De esta forma, la policía cada vez más se recubre de una estética que la aleja de esos "elefantes uniformados que entran pisando las calles y dan miedo", rodeándose de conceptos tan simbólicos como la "proximidad", la "cercanía" o la "empatía"; copiando los formatos propios de la intervención social (se anuncia en panfletos, acude a reuniones de coordinación con escuelas y asociaciones, da charlas en centros cívicos...); adoptando en su trabajo el lenguaje de lo social ("trabajo en red", "reinserción", "menores en protección", "absentismo"); autocensurándose si en una conversación se le escapa a un agente "moros" en lugar de "árabes", e incluyendo en su repertorio retórico "análisis sociológicos":

Eso no quiere decir que el tema de las bandas se vaya a erradicar, porque eso es imposible: los chavales vienen aquí con esa cultura de bandas y aquí no se enteran de nada: en el instituto los bajan la edad de escolarización y les meten con chavales que son muy pequeños, se ven viviendo en habitaciones hacinados, su padres todo el día currando y ven a los blancos como motos y móviles... pues es normal, se juntan él y su colega y listo (Entrevista con agentes tutores de la policía municipal, mayo de 2012).

Esta "nueva" policía debe rendir cuentas "a la sociedad" de su actuación y eficacia, transparentar su gestión en aras de ganar confianza ciudadana, e incluso ser capaz de generar figuras nuevas específicas para el trabajo con las poblaciones más "débiles", como es el caso de los agentes tutores de la policía municipal, encargados de las intervenciones con menores y de los que hablaremos en profundidad un poco más adelante.

La estetización de la policía, síntoma visible del tránsito del paradigma del orden público al de la seguridad ciudadana, y su asociación cada vez mayor con la intervención social - que cristaliza en una creciente colaboración, no sólo en las calles, sino también en los despachos-, posibilita un proceso de legitimación social que otorga a los cuerpos de seguridad un respaldo inédito hasta este momento. Dicho respaldo permite a la policía salir del estigma represivo que la acompaña, penetrar en campos de lo social hasta entones vetados y presentarse a los ojos de los ciudadanos como un servicio público más, casi al mismo nivel que, por ejemplo, la educación o la sanidad: 
Meter a la policía en los institutos era un pecado carnal, era horroroso... pero ahora hemos entrado en los institutos, hemos entrado en los servicios sociales, hemos entrado en un montón de puertas que si no las teníamos cerradas las teníamos sólo entreabiertas... (Entrevista con agentes tutores de la policía municipal, mayo de 2012).

En paralelo, esta creciente legitimación social sirve de freno a las críticas que levanta, como hemos visto, dentro del propio sector de la intervención social la asociación y colaboración cada vez mayor entre ambas figuras. Sin embargo, la estetización policial no modifica, insistimos, su lógica de actuación, que pasa siempre por entender que un trabajo eficaz es aquel que acaba con la detención y/o el escarmiento del infractor. En una entrevista mantenida en mayo de 2012 con varios agentes tutores de un barrio de Madrid, éstos mostraban su desorientación al sentir que hacían "de bisagra entre los agentes que sí pueden actuar" (el Grupo de Menores de la Policía Nacional — GRUME — con los más jóvenes y el resto de sub-cuerpos de la policía con los mayores de edad), dejando patente que para lo que ellos entienden que debe ser una "actuación policial", 'detener', les faltan herramientas: "al final lo que deseas es que los chavales cumplan los dieciocho para que se les pueda trincar". Otros agentes tutores apostillaban de forma firme y seria: "somos policías, no educadores sociales. Eso tiene que quedar claro".

Tal y como hemos señalado, el desplazamiento afecta también a los trabajadores de lo social: al mismo tiempo que la policía se estetiza, éstos amoldan algunos rasgos de su trabajo a una lógica cada vez más cercana a la actuación policial. En realidad, el arte de policiar - en el vocabulario de Michel Foucault -, forma parte de la genética del Trabajo Social. La profesión, fruto de un contexto de fuertes desigualdades sociales generadas en el capitalismo industrial, ya nació imbuida de los valores disciplinarios que asignaban a nuevas figuras, primordialmente femeninas, - primero voluntarias (visitadoras sociales) y después profesionales (asistentas sociales) - , una labor moralizadora que se combinaba con la dispensación material a los "pobres verdaderos", para "sistematizar" y "racionalizar" la ayuda.

Sin embargo, los trabajadores sociales del S. XXI — y cada vez más los educadores y mediadores - han ido consolidando, a demanda de la Administración (aunque en algunos casos secundada con gran entusiasmo), sus pretéritas tareas inquisitorias sobre las familias pobres (con el reclamo continuo de certificados, memorias e informes que, en muchas ocasiones, implican más horas de trabajo que la propia intervención), introduciendo paulatinamente un sesgo securitario en su gestión. Alejados cada vez más del barro y de quienes lo habitan, los dispositivos de intervención social se despliegan generalmente a demanda de los gobiernos autonómico y municipal, y en respuesta a una construcción desde arriba, por parte del aparato legal-policialmédico-mediático, de determinados sujetos o problemáticas sociales como objetos de intervención. Paulatinamente, se adopta un lenguaje técnico alrededor de las "figuras y los indicadores de riesgo", de los sujetos responsables de dicho riesgo o del daño ("menor infractor", "agresor") a los que contener - en un tratamiento cada vez menos indulgente-; y de "las personas vulnerables" a las que defender. Y, poco a poco sus competencias comienzan a responder cada vez más a las necesidades de 
contención del sistema, unas necesidades que obvian todo análisis de las causas sociales del problema y los alejan de cualquier estrategia de cambio que vaya más allá de la mera actuación como "apagafuegos" del "problema" a golpe de "urgencias":

Pues que a ti la Administración te exige una serie de cosas... Si estás trabajando en protección y el chaval no viene a la hora, estás obligado a denunciarle... (Entrevista a un/a trabajador/a social asalariado en una empresa de intervención social, otoño de 2009)

A nosotros lo que nos gustaría es poder trabajar con los chavales de barrio antes de que se generasen problemas. Poder tener espacios con ellos para el desarrollo de habilidades sociales y todo eso. Pero la realidad es que sólo nos llaman cuando hay problemas: cuando se presenta un caso de absentismo escolar, cuando se abre un expediente y todo cosas así. Sólo somos la respuesta a un problema. Y parece que lo único que les interesa es que esa respuesta sea lograr que el chaval deje de complicar las cosas, nada más (Entrevista a un/a trabajador/a social, asalariado/a en una empresa dedicada a la intervención social, primavera de 2009).

Progresivamente reducida la labor de estos profesionales a la contención de los riesgos y de las insatisfechas demandas sociales, no debe extrañar la construcción de refugios bélicos y trincheras en la profesión frente a los usuarios. El énfasis en la seguridad del profesional por el "riesgo a agresiones" es cada vez mayor: medidas disuasorias, como un manual del Colegio de Trabajadores Sociales de Madrid para "prevenir las agresiones"; medidas de prevención situacional, como los vigilantes de seguridad en los centros de servicios sociales; o medidas de socorro, como los "botones antipático" que se instalan en las mesas de algunos profesionales, no son sino el símbolo de la definitiva ruptura de la alianza con aquellos que se sientan en frente. Más allá de los vínculos estrechos que muchos profesionales logran con "sus usuarios", la estructura de la institución y los roles asignados reducen las alianzas a "acompañamientos" en el proceso de descenso social de los acompañados. Las agresiones a profesionales no son en absoluto frecuentes, pero tampoco resulta casual que algunos se nombren apesadumbrados como "antidisturbios sociales", conscientes de que su trabajo de contención es el único que pueden hacer en tiempos de crisis.

Fruto, entonces, de este doble desplazamiento, proliferan en los barrios "policías de proximidad" y "oficinas de denuncia ciudadana", que performativamente intentan transmitir esa "cercanía" más propia del trabajador social de calle, mientras que en centros de reclusión como los Centros de Internamiento de Extranjeros (CIE), donde en un régimen semicarcelario se interna a los migrantes en situación irregular por un periodo máximo de 60 días para facilitar —en teoría - su expulsión, algunas instituciones (por boca de la anterior Defensora del Pueblo) proponen como medida que debería adoptarse para mejorar las garantías en los CIEs, la sustitución de los policías por trabajadores sociales. Además, cada vez son más los dispositivos en los que ambas figuras trabajan juntas — como es el caso de los "Puntos de Encuentro Familiar" o los Equipos de Trabajo con Menores y Familias (ETMF) - y muestran mayor confluencia. 
Todo ocurre, pues, como si, en el contexto actual, la mano izquierda del Estado operase de manera coordinada con su mano derecha - mano que trata de volverse invisible- (Wacquant, 2010: 422). Este enlace no es meramente fruto de la "necesidad" o la consecuencia obligada de los recortes presupuestarios. En realidad responde, como el propio Wacquant indica, a las exigencias de las nuevas filosofías de gobierno que acompañan a las políticas sociales propias del sistema neoliberal. Por tanto, para entender cuál es el origen y la lógica que amparan estas transformaciones, es necesario detenerse a desentrañar los postulados desde los cuales emerge el abordaje neoliberal de lo social.

\section{Título I: de la intervención desde el riesgo}

Un primer rasgo de las políticas sociales neoliberales es su paulatina renuncia a los mecanismos de redistribución de recursos y rentas en pro de una apuesta por la gestión desde la desigualdad social. Y es que, desde una perspectiva que busca hacer que lo social funcione a la manera del mercado, las desigualdades sociales no son sino palanca del deseo y estímulo de la rivalidad y la competencia, auténticos motores de lo social. En términos sociales, las consecuencias de esta forma de gubernamentalidad implican unos costes elevados si se piensan en relación a la estabilidad social. La multiplicación de las desigualdades sociales, junto con la instauración de la inestabilidad y la competencia como ejes gravitatorios de la producción de bienestar y progreso, trasladan a lo social todas las ventajas del modelo empresarial, pero también sus riesgos. Al igual que el modelo económico neoliberal ha demostrado que las sacudidas pueden cobrar una magnitud nada desdeñable, lo social también devuelve la amenaza constante de crisis en sus movimientos.

De esta forma, a las políticas sociales no les compete reducir la desigualdad sino orquestar los dispositivos necesarios para la detección y contención de aquellos "puntos de inestabilidad" en lo social que podrían desembocar en fenómenos disruptivos y potencialmente peligrosos para el buen funcionamiento - competitivo, productivo - de la población. El neoliberalismo se sirve así del Estado del Bienestar - y, en concreto, de los dispositivos de protección e intervención social—que, lejos de desaparecer, invierte sus finalidades para funcionar como pieza clave en la detección del riesgo, la contención de los posibles focos de inestabilidad y el gobierno de las conductas. Con más elocuencia lo expresaba un trabajador de lo social en un poblado chabolista de la periferia de Madrid:

[Esta zona] ha estado siempre abandonada, y cuando empezaron a especular allí y se iniciaron los derribos... ¡Qué casualidad! Lo primero que meten es a servicios sociales... Desde que empezó la conflictividad han puesto a servicios sociales... Para nosotros es una estrategia clara de desmoviliación y control. Han sido los primeros y los únicos servicios públicos que se trasladan. No hay ni escuela, ni centro de salud.

Así, gran parte de las operaciones de intervención social se encuentran dirigidas a la detección del riesgo, de las situaciones conflictivas que pueden poner en jaque el equilibrio social. La centralidad de la noción de riesgo se introduce en los 
últimos tres lustros en las políticas sociales en las distintas legislaciones en materia de protección social. Y, poco a poco, el discurso en torno al riesgo acaba sobredeterminando la forma que toman las intervenciones sociales.

De esta forma dispositivos y herramientas de detección del riesgo van colonizando las esferas del trabajo social, poniendo a los profesionales a pesquisar en sus despachos y a patrullar por parques y calles. Así, pese a que la sensación generalizada entre trabajadores es que los sistemas de recogida de información — como Civis, la aplicación informática de los Servicios Sociales del Ayuntamiento de Madrid - son bastante fallidos en su diseño y en su funcionamiento, sin embargo sirven para proporcionar importantes orientaciones a la gestión: su eficacia no estriba tanto en su utilización para efectuar planificaciones a priori como en su validez para aportar información que permita responder con programas ad hoc capaces de apagar el fuego allí donde se ha detectado riesgo de incendio. En aras de garantizar el conocimiento y la vigilancia de la sociedad, la Administración debe volverse flexible y omnipresente, ser capaz de penetrar en todos y cada uno de los recovecos de lo social, adentrarse en la complejidad social para captar con la mayor precisión posible todos sus movimientos:

Al final, el ciudadano en la calle percibe un cambio 15 años antes de que lo percibe la Administración, y luego la Administración se da cuenta, articulamos presupuestos y 25 años más tarde estamos empezando a actuar mínimamente ante esa circunstancia ¿no? Sin embargo, los trabajadores que están sobre el terreno nos van dando pistas muy rápido de muchas cosas (Entrevista al responsable de un dispositivo de análisis e intervención social, primavera de 2008).

Surgen de esta forma dispositivos como el "Proyecto Antenas" — una red heterogénea de informantes que prestaría su opinión sobre el clima de convivencia en la ciudad en momentos calientes, como un atentado islamista-, o el Servicio de Vigilancia del IRIS, el SIVIRIS, encargado de detectar el afloramiento de nuevas construcciones chabolistas o "asentamientos ilegales", que ilustran de manera rotunda los esfuerzos destinados a la detección del riesgo.

Sin embargo, estos dispositivos tan sólo constituyen un paso más en la formalización de un mecanismo que funciona, de hecho, desde hace tiempo: la monitorización de lo social es posible per se gracias a la miríada de agentes de lo social desplegados sobre el terreno como consecuencia del propio desarrollo de la intervención social. Programas y dispositivos aparte, la monitorización y vigilancia del devenir social pueden desplegarse por medio de procedimientos mucho más cotidianos, engarzados a las actividades diarias que, de un tiempo a esta parte, son constituyentes de la práctica del trabajo social. Así, todos y cada uno de los dispositivos de intervención social puestos en marcha por las administraciones públicas — tanto de forma directa como externalizada - conllevan la documentación sistemática no sólo del desarrollo de las actividades desarrolladas, sino de una infinidad de variables vitales de los sujetos implicados: 
Ahora nos piden que rellenemos un cuestionario con el número de sin papeles que vienen a clases y cuáles de ellos trabajan. Es cómo si hiciéramos de estadistas para el Ayuntamiento, porque yo no entiendo por qué tanto énfasis en esos datos y luego nadie nos pregunta si vienen a las clases, cuántos aprueban, cómo valoramos su progreso, etc. (Entrevista a un/a trabajador/a de un dispositivo institucional, invierno de 2008).

Otra de las estrategias puestas en práctica en los últimos años ha sido la extensión de los espacios públicos como el lugar predilecto para la intervención social: la calle, como espacio natural de lo social en movimiento, pasa a ser considerada un escenario privilegiado desde la que articular los dispositivos de monitorización y contención de los posibles focos de inestabilidad detectados. Así, en los últimos años hemos asistido al surgimiento o la consolidación de figuras como la de los educadores de calle, dinamizadores de parques y espacios públicos, mediadores... La calle como espacio de monitorización de la realidad, pero hábilmente complementada con el despacho como espacio de decisión. Tal y como se significa este trabajo "policial", son precisamente las figuras tan jóvenes y abiertas como precarias y flexibles - educadores sociales - las que se emplean en él, lo cual dificulta de una manera mucho más eficaz cualquier similitud con el control. Detección y contención de las situaciones de riesgo aparecen pues como prioridades marcadas desde arriba, para colarse cada vez más como prioridades sentidas entre los distintos profesionales del trabajo social:

\section{¿Qué objetivos te marcas en un trabajo?}

Prevención de conductas de riesgo: relaciones sexuales de riesgo, respecto a consumos, por lo menos que puedan tomar sus decisiones de forma responsable, en general, respecto a todas las oportunidades que se les brindan. (Entrevista con un profesional de la educación, mayo de 2012).

Demos un paso más en nuestro análisis de la implicaciones de una intervención social construida sobre el discurso del riesgo. Y es que el "riesgo" no sólo puede detectarse, también puede calcularse: sin duda, resulta mucho más eficaz adelantarse a una disrupción conociendo con la mayor exactitud posible bajo qué condiciones puede producirse la amenaza. Es ese desplazamiento, que tan brillantemente situó Robert Castel (1986), de la noción de peligrosidad a la de riesgo. Si bien el peligro lo encarna una situación concreta que se supone como un ataque/desafío al resto del conjunto social, el riesgo no necesita de ese poso de concreción para asentarse. La idea de riesgo no remite a un sujeto o a un hecho concreto, sino a un conjunto de factores abstractos que son susceptibles de producir un riesgo:

En los mecanismos introducidos por la política, el interés estará en principio... en las previsiones, las estimaciones estadísticas, las mediciones globales; se tratará... no de modificar tal o cual fenómeno en particular, no a tal o cual individuo en tanto que lo es, sino, en esencia, de intervenir en el nivel de las determinaciones de esos fenómenos generales [...] (Foucault, 2006: 160). 
En términos de gestión de poblaciones, no se trata tanto de defenderse ante lo concreto (que también) cuanto de prevenir interviniendo sobre 'datos abstractos o factores que hacen más probable la materialización de comportamientos indeseables' (Castel, 1986: 229).

Así, una de las nuevas funciones de los dispositivos de protección e intervención social pasa a situarse en la definición de todo un conjunto de factores y umbrales de riesgo, que cuesta no asociar a los mapas de peligrosidad tan extendidos dentro de las políticas securitarias. Por poner tan sólo un ejemplo, el Observatorio de la Vulnerabilidad Urbana, desarrollado por la Dirección General de Suelo y Políticas Urbanas del Ministerio de Fomento, elabora periódicamente un catálogo de barrios que han sido clasificados por el Ministerio como barrios vulnerables estableciendo una serie de indicadores - tasa de paro, porcentaje de población analfabeta y sin estudios, carencias en las viviendas y tasa de inmigración - cuya confluencia determina que una unidad social concreta tenga una alta exposición a riesgos, incertidumbres y fragilidades que podrían, en un futuro, derivar en situaciones problemáticas para el conjunto social. Algo bien parecido nos encontramos en distintos protocolos de actuación de entidades que trabajan con menores, donde los profesionales cuentan con un complejo baremo que les permiten clasificar como leve, moderado o grave el riesgo en el que se encuentra el menor en función de variables sanitarias, conductuales, socio-económicas, etc. Nuevamente la Ley de Protección del Menor nos ofrece un último ejemplo al citar todo un conjunto de "factores de riesgo y dificultad social" que los poderes públicos deben disminuir con su actuación.

Cuando el riesgo se convierte en una construcción a priori, se vuelven entonces necesarias actuaciones concretas hacia un conjunto de la población no por lo que han hecho, sino por lo que en tanto que miembros de un determinado conjunto de población se piensa que pueden hacer: previsión por parte del profesorado que un chaval inmigrante vaya a fracasar en la escuela por el mero hecho de serlo, previsión de un médico de que una enfermedad sea consecuencia de un descuido familiar, etc. Los factores de riesgo son móviles, relativos, pero mantienen ciertas constantes que se repiten por las cosas que hacen/les pasan a los sujetos y, sobre todo, por las características de los propios sujetos - hecho migratorio, pobreza, edad, estética...-

Resulta reseñable el hecho de que dichos umbrales no se midan tanto en función del peligro que corre la persona del menor, como atendiendo a los riesgos de desorden/disrupción —indisciplina, conflictos, agresividad, embarazos, conductas disfuncionales - que provoca en su entorno, y sobre los que siempre se cruza, irremisiblemente, la variable de clase:

Nosotros desde Servicios Sociales tenemos unos ítems, que marcan una situación de riesgo: riesgo leve, riesgo grave... Nosotros entraríamos en riesgo leve, que es absentismo escolar, posible desatención familiar, algún problema de salud mental que hace que el chico la esté liando en el colegio y los padres no sean capaces de darle una respuesta por venir de clases bajas... (Entrevista a educadores sociales, mayo de 2012). 
La definición de factores y umbrales de riesgo se produce a través de cálculos estadísticos - y aderezados con no pocas dosis de un neomoralismo refinado, en tanto se recubre de un lenguaje cientificista-, que muchas veces quedan bien alejados de la sensación subjetiva de los actores, rara vez preguntados en el proceso. Al fin y al cabo, dentro de esta lógica de gestión, la amenaza es tal en tanto que afecta al "normal" desarrollo de una población: uno no supone necesariamente un riesgo para sí mismo, lo es para con el resto.

En paralelo, este proceso acaba por introducir una escisión, quedando fragmentados los sujetos intervenidos entre los que están "en riesgo" —abordados como víctimas - y los que son "de riesgo" — abordados de manera culpabilizadoraLa hiperprotección o la hipervigilancia son los efectos de este marcaje, si bien es frecuente que los sujetos ocupen una posición liminar, oscilando frecuentemente de un lado a otro de la balanza, generalmente hacia el lado de la culpabilidad: así, por ejemplo, un adolescente que empieza cierto coqueteo con una "banda" deja de ser un chico "en riesgo", con conductas de riesgo que haya que prevenir y reprimir, para convertirse él mismo en un sujeto "de riesgo", al que hay que contener. La propia institución es muchas veces la responsable de dicho movimiento: un adolescente "en riesgo" puede pasar a ser "de riesgo" a partir de un informe de un trabajador social o de un diagnóstico establecido en una reunión de un ETMF. Pero es sobre todo una intervención policial la que determinará el cambio de enfoque: de la vigilancia sobre la relación de su entorno con él se pasará a la vigilancia de su relación con el entorno:

\begin{abstract}
Porque muchas veces de lo que no os dais cuenta cuando se trabaja en calle es que un grupo de chicos a veces acaba por hacer esclavo al educador y ya no ve en su conjunto, ve solo a sus chicos y no a las víctimas... El educador social tiene que ver más allá, a esas víctimas... Hay que verlo todo en conjunto, cuando se ve en conjunto es más fácil trabajar: ver al chico que puede ser un futuro agresor, ver a la posible víctima, y a otros profesionales que trabajan con ellos (Extracto de la intervención de un policía municipal en un acto público, mayo de 2012).
\end{abstract}

Es desde esta óptica desde la que proponemos interpretar ese paulatino acercamiento entre las lógicas policiales y las del trabajo social: la intervención social hecha desde la noción de riesgo hace que cada vez más los problemas sociales se aborden como problemas de seguridad y orden público, habla de sujetos/barrios/situaciones que encarnan un peligro y a los que es necesario contener, remite a ritmos de urgencia y explica, por lo tanto, que se tienda a una progresiva policialización de los conflictos en sus modos de abordaje. Cuando lo social es contemplado y gestionado desde el prisma del riesgo, la intervención social pasa a realizarse desde la óptica del control, la contención, la negatividad y el miedo. Las antiguas "chiquilladas" — pequeños hurtos o peleas-, hoy provocan la intervención institucionalizada sobre los chavales de educadores y trabajadores sociales, previo paso por comisaría.

$Y$ es desde esta filosofía del riesgo también que puede entenderse la presencia cada vez mayor de agentes policiales en ámbitos que hasta hace muy poco eran exclusivos de la intervención social. Eso sí, para dar este paso con la mayor legitimidad 
social posible es necesario, como referíamos con anterioridad, que la policialización del trabajo social se complemente con una trabajosocialización de la policía. La figura paradigmática que condensa esta nueva inspiración es, sin duda, la de los agentes tutores de la policía municipal. Los agentes tutores son la cara más amable y social de la policía en su trabajo con los chavales. Sobre el papel, su labor es de "protección de los menores de edad". En la práctica, esto incluye un trabajo con las comisiones de absentismo, con Servicios Sociales (para intervenir en familias "problemáticas"), con educadores y asociaciones de intervención social, y con los colegios de la zona (respondiendo a llamadas que se hacen desde los centros, vigilando las entradas y salidas para evitar el tráfico de drogas, etc.). Los agentes tutores representan a esa otra policía con la que se llama a colaborar en tiempos de recortes y crisis, en una argumentación que acaba obviando que más allá de los procesos de transformación estética - los agentes tutores son una suerte de "secreta a voces", figuras conocidas por todos los chavales, pero cuya presencia vestidos de paisano es suave y disuasoria-, los objetivos de intervención de unos y otros, así como los principios, sobre el papel, desde los que se plantean, son dispares, cuando no opuestos —amén de las desconfianzas que dicha colaboración levanta entre los sujetos de la intervención-. Una breve indagación en sus discursos y análisis de la realidad con la que trabajan, nos muestra cómo, frente al progresismo terapéutico de buena parte de los trabajadores y educadores sociales - trabajo a largo plazo-, ellos siguen siendo partidarios de la "mano dura", acciones contundentes y neodisciplinarismo:

El más joven dice 'parte de que esto es un barrio muy deprimido’. ‘Deprimido? — pregunta irónicamente otro más veterano- pues yo los veo la mar de relajados y viviendo muy bien, con sus BMV y sus pisazos del IVIMA... Yo creo que más que un barrio deprimido es un barrio depravado'. 'Muy desestructurado', apostilla el más joven.

En este barrio hay muchos dominicanos y árabes realojados y eso es un sustrato muy bueno para las bandas.

El chaval que empieza a delinquir con pequeñas cosas ya no sale... Por mucho que trabajes con él, la cosa va a terminar mal... Seguirá con la venta de droga, luego delincuencia a mayor escala y de ahí a la cárcel... Unas perlitas, eso es lo que tenemos aquí... Hasta que no les detenemos, nada de lo que haces sirve (Notas de entrevistas con agentes tutores de la policía municipal, mayo de 2012).

A pesar de la clara distancia que existe entre los agentes y la filosofía más propia del trabajo social, lo cierto es que no son infrecuentes los casos en los que los distintos agentes sociales - incluido el vecindario - acuden a ellos como un "comodín al que utilizan colegios, asociaciones y familias cuando la cosa se les va de madre", lo cual nos remite a una policialización de la intervención y de los conflictos sociales, pero sin los inconvenientes de la intervención puramente policial. Algunas entidades son bien conscientes de lo problemático de esta tendencia, optando por no formar parte de ella: 
Muchas asociaciones son antipolicía, no quieren saber nada de nosotros (...) es que en muchos sitios parece como si estuvieran todavía en la guerra civil, nos ven como el enemigo". Me cuentan cómo hay veces que algunas asociaciones les llaman preguntando por el programa de los agentes tutores, conciertan una entrevista y cuando van allí y se dan cuenta de que son policía no quieren saber nada de ellos (Notas de entrevista con agentes tutores de la policía municipal, mayo de 2012).

Pero en otras muchas, esta relación es estrecha y no se encuentra en absoluto problematizada. En sus palabras se delata el queme por no verse reconocidos como útiles por algunos profesionales y su puesta en valor a través del discurso de la emergencia: "al final somos los que intervenimos". Es precisamente el emergencialismo una de sus aportaciones a la intervención sobre lo social: cuando los riesgos no han podido ser prevenidos y sus efectos contenidos, se requiere una intervención reactiva que ellos encarnan mejor que nadie. De ahí que sean los agentes favoritos de las intervenciones contra los temas que generan "alarma social", como las bandas latinas.

Sea como fuere, el marcaje a partir del discurso del riesgo de ciertos individuos y colectividades tiene efectos performativos, no sólo sobre el objeto de la intervención - sobre el que acaba generando un habitus de inferioridad y humillación-, sino sobre el resto de la sociedad: el marcaje a determinados grupos o franjas de población, y las intervenciones sobre ellos, acaban traduciéndose en la producción de temores que se propagan por el conjunto del cuerpo social: así, los riesgos no son únicamente definidos desde arriba, sino que se co-producen desde abajo gracias a la proyección de imágenes de peligrosidad que son reapropiadas en el cotidiano.

Con los últimos recortes en los dispositivos de Servicios Sociales e intervención social, los programas de corte más preventivo son los que más se han visto afectados. Empleando la retórica protagónica de la crisis - "haber vivido por encima de las propias posibilidades", "haber gastado más de lo que se ingresaba"-que, precisamente, oculta que los "excesos" fueron una apuesta de la propia gestión cuando se trataba de insuflar oxígeno a la economía con políticas de inversión pública y redistribución a favor del sector privado, llega el momento de establecer prioridades. Así, en los últimos años hemos visto cómo se reducen los dispositivos de "acogida" e "integración" en materia migratoria — sólo desde 2009 se ha suprimido el Servicio de Mediación Social Intercultural, la Escuela de Convivencia Intercultural, el Servicio de Apoyo a la Gestión de la Diversidad, el Observatorio de las Migraciones y la Convivencia Intercultural, proyectos de integración en barrios...- mientras que en algunos distritos de la capital se ha puesto en marcha un programa destinado a los hijos de los migrantes para prevenir su posible enganche con las bandas. El presupuesto asciende a 130,000 euros. Aunque esta tendencia no sea novedosa, se acentúa poco a poco.

\section{Título II: de las amenazas que emergen}

Cuando las medidas preventivas han fallado, han alcanzado sus límites o simplemente se ven sorprendidas por una irrupción social, las amenazas latentes, los riesgos, "emergen". En esas emergencias se rompe la normalidad, afloran las 
tensiones que permanecían "dormidas" y se puede poner en jaque el orden social. Sin embargo, la gestión neoliberal de lo social, al situarse en el interior de la realidad dejando que las cosas ocurran, asume estos muchos pequeños "males": desde esta tecnología de gobierno, las emergencias sociales se conciben como inevitables en cuanto síntoma de la competencia en una sociedad organizada a la manera del mercado, lo cual no obsta que deban ser orquestados protocolos y técnicas para atenderlas. La centralidad de la contención de la emergencia en los objetivos de la gestión de lo social explica, junto con el discurso del riesgo, el doble desplazamiento acontecido en las políticas sociales que venimos explicando. Por eso, le dedicaremos nuestra atención en estas últimas páginas.

En los últimos años asistimos a un creciente peso de la atención a las emergencias y a su racionalización sistematizada dentro la intervención social. En los despachos de los Servicios Sociales, los turnos de guardia orquestados para atender a las "situaciones de emergencia" van cobrando cada vez más peso, a la par que se habilita un conjunto de recursos específicos —alojamientos, ayudas económicas, medidas de protección... - cuya disponibilidad contrasta con la manifiesta escasez de dichos recursos para atender situaciones menos acuciantes. Del mismo modo, y al hilo de urgencias y alarmismos mediáticos, desembarcan en los barrios recursos de emergencia que desaparecen con la misma rapidez con la que llegaron una vez que la situación se ha "canalizado". Pero es, sin duda, la puesta en marcha por el Ayuntamiento de Madrid del Samur Social en 2004 - cuya "marca", presume uno de sus responsables, es reconocida en toda Europa - el mejor ejemplo del protagonismo de la atención a las emergencias sociales por parte de los Servicios Sociales: un dispositivo que cuenta con un buen número de profesionales uniformados de color azul celeste, varias unidades móviles desplegadas para detectar por las calles a personas en situación grave de exclusión, una central de atención telefónica que recibe llamadas derivadas por el teléfono de emergencias y una serie de plazas propias o concertadas con albergues, pensiones y hoteles para dar respuestas de alojamiento por un periodo máximo de una o dos semanas - sobre todo en aquellas situaciones derivadas por los propios trabajadores de los Servicios Sociales cuando se les presenta una "emergencia" en su despacho- . Tal y como se define en un documento de trabajo sobre las funciones del Samur Social, la emergencia es, cada vez más, una prioridad en nuestras sociedades, no solo en términos de gestión, sino también en tanto que demanda ciudadana:

Las Emergencias Sociales constituyen una realidad que cada vez se hace mas presente en nuestra sociedad. Sin lugar a dudas, los ciudadanos reclaman un mayor grado de seguridad y por este motivo, ante las posibles situaciones imprevistas de desprotección solicitan la intervención de las instituciones y entidades públicas. En este sentido, la red de Servicios Sociales siempre ha proporcionado diferentes respuestas a las situaciones de desprotección que se producen de forma inesperada y que suponen, para muchos casos, situarse en una situación de riesgo y vulnerabilidad social. Sin embargo, hay que reconocer que en los últimos años, por una parte la ciudadanía reclama una mayor y mejor respuesta institucional ante dichas situaciones. De igual modo, de forma paralela, se cuenta en el Ayuntamiento con un 
importante Servicio Social Especializado en la atención a las Emergencias Sociales (Samur Social).

Las actuaciones centradas en la necesidad de dar respuesta a la emergencia social imponen a la intervención social unos ritmos y formas de trabajo que, nuevamente, nos remiten a aquellos más propios de la lógica policial. Así, en primer lugar, hacen prevalecer el trabajo a demanda — en respuesta a una emergencia-, sobre el trabajo proactivo y/o de prevención. Ante la alarma de un vecino por la presencia cercana de un acontecimiento/sujeto en riesgo — que ya ha pasado a ser considerado de riesgo - "teníamos que ir siempre cuando llamaba un ciudadano, porque estaba un indigente en su portal, aunque no pudiéramos hacer nada con la persona y ésta no quisiera nada de nosotros, pero teníamos que ir para que se nos viera", afirmaba una ex-trabajadora del Samur Social. Al igual que las patrullas policiales, "que funcionan a demanda, cada vez que la emisora suena", los trabajadores del Samur se activan cuando entra una llamada a centralita. Pero no sólo ellos: en líneas generales, el contenido de la intervención de la gran mayoría de los profesionales de lo social sigue las mismas líneas...:

Asistimos asimismo, a un claro cambio de enfoque de los dispositivos de intervención social: quedan olvidadas todas aquellas líneas que supusieran la participación y el empoderamiento de las personas y las comunidades en la construcción del cambio, para centrarse en la creación de dispositivos de contención del malestar social, todo ello mientras observamos en lo cotidiano de nuestro trabajo un aumento alarmante de la pobreza y la exclusión (Grupo de trabajadoras del servicio de Asistencia Vecinal de la Comunidad de Madrid, ASIVECAM).

Tienes un trabajo que te gusta, que es para lo que has estudiado...pero luego otra cosa es la realidad, tienes que ir atajando problemas, haciendo lo que te dicen... Lo que nos queda de la intervención social no es tanto lo que tu sueñas sino lo que es (Entrevista a educadores sociales, mayo de 2012).

Un trabajo a demanda que requiere, en segundo lugar, de decisiones "fuertes" y respuestas rápidas y eficaces que calmen las ansiedades de la gente. En consecuencia, este trabajo impone el ritmo del corto-plazo a través de los protocolos de atención a las "urgencias" en los Servicios Sociales de cada barrio. Se trata de superar esa sensación de ineficiencia que despierta la intervención social para asemejarse poco a poco a las capacidades de respuesta que generalmente se atribuyen a las fuerzas de seguridad:

El problema es que nosotros ante una acción tenemos que tener una capacidad de reacción inmediata.... Si pasa algo, yo tengo que dar una salida. Y los educadores no entienden esto: ellos entienden que lo que hay que hacer es un trabajo a largo plazo y luego pasa lo que pasa...

Son funcionarios, y tardan meses en atenderte... por eso las familias cuando tienen un problema acuden a nosotros y no a Servicios Sociales, porque no pueden esperar todo ese tiempo... ¿No hay médicos las 24 horas del día? Pues en Servicios Sociales 
debería ser igual" (Entrevistas con agentes tutores de la policía municipal, mayo de 2012).

Sin embargo, el trabajo a ritmo de emergencias no sólo requiere de disponibilidad y eficacia: implica también un enfoque mediante el cual las distintas problemáticas se aborden sólo desde aquello que aflora superficialmente — causando alarma-, evitando sumergirse en las raíces del problema. Y es que esta lógica de funcionamiento se basa en lograr un restablecimiento del orden social lo más rápido posible, sin plantearse su reversión "removiendo" más de lo necesario. Esto sucede así aún incluso contraviniendo la ley económica de los costes y los beneficios: valga como ejemplo que, ante una familia con menores que va a ser desahuciada de su vivienda, los profesionales no intervienen sobre la entidad bancaria o el juzgado —origen social del problema en cuestión-, ni apoyando la organización de redes vecinales para frenar los desahucios - prevención comunitaria-, ni asumiendo el coste del alquiler o la hipoteca de la familia - una forma de asistencia que podríamos designar como primaria-, sino que la solución de la institución a estas situaciones, una vez cubierta la emergencia mediante un alojamiento transitorio - asistencia a la "emergencia" - y cuando fracasa el apremio a los implicados para que "solucionen su situación" o fuercen el "apoyo natural" de la familia extensa -intervención persuasiva o coactiva-, no es otra que la de tutelar a dichos menores y retirar su guarda a quienes "no han velado por sus necesidades", invirtiendo en ello unos recursos económicos superiores a los que hubieran sido necesarios para hacer frente al pago de la vivienda que la familia no podía afrontar. De haber incidido sobre las causas sociales o institucionales, o sobre los diques comunitarios del problema concreto, se habrían subvertido las reglas de la sociedad-mercado. El orden social se superpone en éste y otros casos a la rentabilidad económica que cabría esperar de la gestión neoliberal, porque en realidad lo verdaderamente neoliberal es la forma intervenir sobre lo social.

Es de esta superficialidad de la intervención centrada en lo emergente - lo que los propios trabajadores sociales designan de manera resignada como "parchear"-, de lo que también se contagian los profesionales que, se supone, deberían realizar un trabajo más preventivo, como los educadores sociales. En sus palabras:

En el trabajo con las familias, que es el grueso de nuestro trabajo porque es donde más demanda hay de servicios sociales, lo hacemos a matacaballo, porque suelen ser casi siempre situaciones de urgencia, y ahí no podemos darle un enfoque más profesional. No queda otra que atajarlas y ya está. Muchas veces no podemos realizar la labor de educador social, sino solamente lo de tapar agujeritos. Digamos que nosotros somos la herramienta que ellos tienen para meter ahí cuando hay un momento complicado (Entrevista a educadores sociales, mayo de 2012).

El trabajo de la emergencia nos remite a la lógica de contención que afirmábamos antes como característica de las formas de gestión de lo social neoliberal. Como si de una red en el fondo del precipicio se tratara, las "situaciones de emergencia social" rebotan y con suerte vuelven a insertarse en el juego social, aunque 
sea pendiendo de las ramas de los árboles situados al borde del abismo — esto es, los estratos más bajos de una sociedad hipersegmentada - : compitiendo por un empleo, por un alojamiento o por una ayuda siempre mínima y escasa. La lógica de esta atención a la emergencia social no es otra que la que Michel Foucault (2008: 217-248) describió para la renta mínima de inserción en el contexto de una política social neoliberal, esto es, un colchón que amortigua el golpe, procura lo necesario para la supervivencia sin que el beneficiario "se acomode", y devuelve al individuo a la competencia social.

Todos estos rasgos que implica la centralidad de la emergencia en la intervención social - trabajo a demanda, decisiones fuertes y rápidas, primacía del corto plazo en las actuaciones, abordaje superficial de contención-, asimilan los modos de trabajo de los profesionales de lo social a los de la policía, cuyo clima de intervención natural es, precisamente, la emergencia. Y en las emergencias, se estrechan también los lazos: atajar el problema de las bandas latinas, acudir a un domicilio tras una demanda de un vecino, asistir en los procesos de desahucio, etc., son extremas circunstancias en las que la seguridad no puede ser sólo cosa de la policía, sino que se consigue - coproduce - gracias a la colaboración de todos. Tal y como apuntaba un trabajador social, "Acercarse el educador y la policía cambia el tono de voz, como si nos reconociéramos en lo mismo..., porque saben que estamos haciendo un trabajo en la calle". En esta colaboración entre unos y otros agentes, en ocasiones se produce cierta rivalidad por hacerse un hueco en el nuevo paradigma de la emergencia:

Porque claro, en este pastel que son las emergencias, hay servicios que tienen copado todas las guindas y todo el chocolate y todo el bizcocho, y entonces, entrar tú es complicado y difícil, pero sobre todo porque hay una dinámica histórica de que no conciben el efecto de lo social en la emergencia cuando resulta que es fundamental e importante, porque además, si ponemos el ejemplo de un incendio, pues está claro, llega el bombero y apaga el fuego, llegan los de protección civil y atienden a los heridos, la policía mientras tanto su papel es acordonar la zona y asegurar que los servicios de emergencia trabajen..., pero claro, tienes que entrar tú en ese juego (Entrevista al responsable de un dispositivo de atención social, junio de 2012).

En tales circunstancias, lo habitual es que se produzca un reparto de papeles entre quienes entran en juego para aplacar la emergencia: la gestión policial se encarga de la contención de los fenómenos más duros y violentos, mientras que a los trabajadores sociales les corresponde realizar una contención de corte más emocional. Las personas al borde del precipicio de la llamada "exclusión social" cuentan, al menos, con un paracaídas que decelera el descenso y le acompaña en su declive social. El "acompañamiento social", término acuñado en el Trabajo Social para dar cuenta del acercamiento del profesional a la subjetividad del otro en sus encuentros, amortigua el momento de crisis y el impacto del trauma. De ahí que la propia actuación de los Servicios Sociales se haya orientado, en épocas de recortes, precisamente a esta función: no importa que se carezca de recursos para dar respuesta a las demandas de la persona en emergencia - vivienda, alimentos, dinero para afrontar un recibo de la luz, etc.—, lo fundamental es que esa persona sea atendida: "el recurso" son los 
propios trabajadores sociales. Su trabajo de escucha constituye un bálsamo fundamental para neutralizar los aspectos más disrruptores y agresivos -hacia el exterior o hacia sí mismas - por parte de las personas en emergencia. El acompañamiento logra, si se efectúa con sensibilidad, un aspecto fundamental: dejar una puerta abierta a la mejoría, generar una esperanza hacia el futuro que logrará reducir los niveles de ansiedad y agresividad de la persona en declive.

Si el trabajo sobre el riesgo busca prevenir y acotar las disfuncionalidades sociales antes de que se desborden, el trabajo desde la emergencia busca reparar lo más rápidamente posible el dique cuando éste no ha sido capaz de contener las aguas. Sin embargo, el emergencialismo dominante en la intervención social cumple otra función nada desdeñable: aliviar las situaciones graves, visibles y socialmente intolerables, transmitiendo la sensación de que en momentos de crisis, las instituciones "actúan", lográndose con ello restablecer una legitimidad que la propia emergencia había puesto en jaque. Así, por ejemplo, el Samur Social, "sobre-actúa" sobre el síntoma: su especialización en la población considerada "sin hogar" le lleva no sólo a trabajar a demanda, sino también a efectuar cierto trabajo proactivo, fundamentalmente en los distritos céntricos, cuyas calles se encuentran destinadas al consumo y el turismo. La pobreza visible no casa con la espectacularización urbana, por lo que es necesario apartarla — y hacerlo de forma aún más visible que la misma pobreza, convirtiendo así a la propia asistencia social en un espectáculo- - Si los profesionales de este dispositivo reciben órdenes de pasearse y dejarse ver por determinadas calles de la ciudad, la labor de los trabajadores de Servicios Sociales cuando realizan "visitas a domicilio" en los casos en los que los vecinos denuncian un conflicto convivencial - visitas, que solo se llevan a cabo en el caso de que las familias denunciadas presenten algún indicador de "riesgo" como ser de origen extranjero, pobre o asociado a prácticas de economía informal- puede interpretarse en un sentido bien semejante. Aunque raras veces resuelva el problema, la visita profesional actúa como elemento inhibidor sobre la familia "ilegítima" y como bálsamo tranquilizador sobre el vecindario — que verá que la Administración, aunque no pueda resolver "su problema", al menos responde-.

Pero sin duda, lo que más hace brillar a los dispositivos de emergencia social son las llamadas "emergencias colectivas". Éstas son muy escasas en relación a las asistencias individuales a personas de/en riesgo, y sin embargo constituyen la labor más visible a nivel mediático. El macro-atentado terrorista del 11 de marzo de 2004 que dio pie al propio surgimiento del Samur Social, el accidente de un avión de Spanair en 2008 en el aeropuerto de Barajas o el derrumbe de un edificio en el distrito de Tetuán en 2010, constituyen los hitos históricos del dispositivo. Para ellas, el Samur Social cuenta incluso con otra cartera de servicios, que incluye habitaciones en una famosa cadena hotelera de categoría media-alta. Su actuación "ejemplar" fue reiteradamente repetida por los responsables políticos y amplificada en los medios de comunicación, que llegaban a informar más de la atención prestada a la emergencia que de la propia emergencia en sí. Sin embargo, una vez que el momento de urgencia remite - y los focos de las cámaras apuntan en otra dirección-, toca "movilizar recursos" y devolver el apremio sobre las situaciones familiares e 
individuales para que quienes ocupan, por ejemplo, la plaza de alojamiento, la abandonen lo antes posible, permitiendo así disponer de plazas libres para continuar el ciclo de la atención y estar preparados para "las futuras emergencias". Y es que la gestión de las emergencias se torna fundamental en tanto que se trata de momentos liminales, en los que pueden producirse importantes disrupciones del orden social. La capacidad de respuesta ante situaciones "no tolerables" legitima al propio sistema mediante una suerte de reparación simbólica que permite seguir gobernando lo menos posible, pero sin transmitir sensación de desgobierno (Foucault, 2006). Un trabajo de apagafuegos de los trabajadores sociales que nunca logra apagar del todo las brasas - como tampoco lo hace, por definición, el trabajo policial一, pero que constituye una labor de enorme valor en lo que al mantenimiento del orden y la legitimidad social se refiere. Un trabajo de apagafuegos que nos recuerda que, al final de todo, la "mejor" respuesta — en términos de gubernamentalidad — es la que proporciona tranquilidad y seguridad al conjunto de la población, por encima de que las situaciones de desigualdad persistan.

\section{Disposición transitoria primera: de la policialización de lo social}

Decíamos al comienzo del presente artículo que las políticas sociales neoliberales se asientan $-\mathrm{y}$ fomentan - la multiplicación de las desigualdades sociales, propiciando de esta forma fenómenos de rivalidad y competencia. Instaurado a la par un paradigma de la escasez (de presupuestos públicos, de puestos de trabajo, de plazas en colegios, de asistencia médica...), la sensación imperante es que nuestra situación, nuestro espacio, las certezas o el cotidiano, pueden verse alterados por la presión que ejercen "otros" por ocupar nuestro sitio. La sensación de inseguridad y el miedo inundan de esta forma al conjunto de la sociedad. Las políticas de gestión de lo social bosquejadas no sólo forman parte intrínseca de este proceso sino que ahondan precisamente en esa inseguridad: al poner el énfasis en una gestión hecha desde el riesgo y la emergencia, desplazan del centro de la cuestión social la preocupación por la desigualdad para poner en su lugar el problema de la seguridad.

Ante la amenaza que la población siente en este contexto de hipercompetitividad, la seguridad pasa a ser la oferta más "natural" de la que los poderes públicos disponen - oferta que, además, tiene la ventaja de ser visible y actuar a corto plazo-. Por un lado, se incide en los problemas relacionados con la inseguridad "objetiva" (si bien asumiendo que el propósito no es utópico - "acabar con la delincuencia"-, sino pragmático - "intentar hacer lo más posible con los medios de que disponemos"-), redistribuyendo los riesgos hacia zonas periféricas o capas sociales desfavorecidas y conteniéndolos mediante estrategias de prevención situacional, como la presencia visible de policía actuando como elemento de disuasión.

Por otro lado, se trata de incidir también sobre los miedos subjetivos de la población, visibilizando la existencia de sucesos y peligros en los medios de comunicación, transmitiendo con la presencia y proactividad policial en las calles (continuos controles de identidad selectivos) que "algo ha ocurrido", y publicitando las intervenciones de los cuerpos de seguridad y los datos de su gestión. Al mismo tiempo que se transmite tensión y se genera la demanda subjetiva de protección, se oferta 
"más policía" para responder al "derecho a la seguridad" (Baratta, 2001) que los ciudadanos necesitan para sentirse como tales —en la medida en que, valga decir, se degradan sus derechos sociales-. El resultado de esta gestión de la inseguridad objetiva y subjetiva es una creciente policialización de los conflictos sociales, cuando no de la propia pobreza, en una suerte de estrategia que Zibechi (2011) define como característica de las políticas sociales neoliberales.

Y es que el desplazamiento de la cuestión de la desigualdad y su sustitución por la cuestión securitaria justifica a la par una política cada vez más represora frente a los grupos que ocupan las posiciones más subalternas, señalados como chivos expiatorios y fuente de la mayor parte de los temores. El control policial se ejerce así de manera variable sobre distintos grupos sociales, dando como resultado una seguridad ciudadana diferencial, o mejor dicho, una seguridad dependiente del grado de ciudadanía. Así es cómo la población de apariencia extranjera, pobre o joven -más aún cuando confluye más de una de estas categorías en el mismo cuerpo- es construida como sujeto de riesgo y objeto de control en los espacios públicos de la ciudad.

El propio Sindicato Unificado de Policía (SUP) reconoce que la mayor parte de su labor se centra en efectuar controles de identidad a población de apariencia extranjera y joven sin que se haya producido ningún delito, lo cual se traduce en una creciente hostilidad por parte de esta población hacia los agentes: el mismo sindicato confiesa la relación entre la creciente interposición de sanciones por desacato a la autoridad y los propios controles de identidad discriminatorios y masivos que efectúan. De esta forma, las intervenciones policiales acaban por producir performativa y jurídicamente aquello que precisamente se supone que deberían evitar.

En un contexto de plena crisis económica como el actual, es posible observar cómo el aumento de las desigualdades y de los umbrales de pobreza no preocupan tanto como las manifestaciones violentas que éstas puedan tener en forma de extensión de la microdelincuencia, de las tensiones y de la conflictividad social. Así, en los últimos meses, el Cuerpo Nacional de Policía ha puesto en marcha una nueva Unidad de Prevención y Reacción (UPR) ad hoc cuyos miembros, conocidos como "los bronce", tienen como objeto la respuesta a las "nuevas formas de conflictividad social". Entre sus funciones, la "prevención de la delincuencia, cuyas acciones variarán en función de las demandas ciudadanas, repuntes de delitos concretos y detección de puntos negros de inseguridad", aplacar algaradas - como las producidas en fiestas y conciertos en los que se concentra población joven - y reprimir protestas de distinta índole — desde los intentos de parar desahucios a insólitos fenómenos como la expulsión de la policía por parte de los vecinos de barrios como Lavapiés-, así como las redadas en busca de asuntos tan variopintos como drogas o personas sin permiso de residencia en España —en términos jurídicos, una simple falta administrativa-. Sus funciones no son nuevas, y su lema, "Restablecemos el orden", no tendría mayor relevancia tratándose de policía si no fuera porque esta unidad surge en un momento en el que la conflictividad social repunta. El aspecto más soft de la policía, aquel que persigue la estetización de algunas de sus figuras e intervenciones individualizadas, se combina en los momentos de tensión con una policía hard que ya no puede centrarse sino 
en el riesgo desbordado y tumultuoso, la amenaza de "desorden" hecha realidad emergente.

\section{Disposición transitoria segunda: de la (in)seguridad como pegamento social}

Este enfoque securitario que venimos describiendo, erigido sobre imaginarios, discursos, normas, prácticas y arquitecturas que colocan en el centro las nociones de riesgo y emergencia, tiene en la policía su figura protagónica y en lo policial una tecnología de abordaje que ha acabado por penetrar en otros campos aparentemente lejanos, como el de la intervención social. Dicho dispositivo permite canalizar las ansiedades de un malestar social complejo hacia colectivos visibles y diferenciados hasta reducirlas a un simple miedo a la criminalidad y la incivilidad, evitando así el cuestionamiento de la violencia estructural y de las relaciones de poder - económicas, políticas, de género, etc.- - que las engendran.

El discurso securitario tiene una dimensión molar capaz de construir enunciados simples que aplanan la subjetividad, al tiempo que hablan precisamente a esa misma subjetividad. La promesa de seguridad, esgrimida por los poderes públicos, pero también por aquellas organizaciones que aspiran a representar a la población, aparece como único pegamento posible en medio de la multiplicación de divisiones, tensiones, enfrentamientos y violencias. Y resulta eficaz como estrategia de gobierno al interponer cortocircuitos simplificadores en el conjunto de problemas que plantea la inseguridad en un contexto de no future: tiene el mérito de mostrar que se hace algo sin necesidad de ocuparse de cuestiones más difíciles y exigentes. Da respuesta a un malestar colectivo y legitima la contención preventiva, precisamente en nombre de ese malestar. De esta forma, puede afirmase que la política de seguridad es una necesidad de la gestión neoliberal de lo social: "la producción y la gestión del sentimiento de inseguridad es, cada vez más, la razón de ser y la forma de legitimación del poder" (Rancière, 2010). El propio modelo hegemónico funciona, además, en espiral y hasta el infinito: a mayor percepción de inseguridad, más represión, y a mayor represión, más sensación de inseguridad. La propia policialización de lo social retroalimenta la atomización del cuerpo social, minando la confianza mutua y la cooperación, y colocando como bisagras sociales a expertos que median en las manifestaciones individualizadas de los conflictos. Expertos que polician - aunque no todos sean policías - desde la cercanía, previniendo con su presencia, monitoreando la realidad, haciendo intervenciones puntuales, vigilando a los sujetos de riesgo, protegiendo a las víctimas, respondiendo con firmeza en los desastres, acompañando en los duelos, tranquilizando las tensiones, persiguiendo a los malhechores y restableciendo el orden cuando es necesario, un orden que la propia apuesta por la desigualdad no puede sino hacer peligrar.

\section{Disposición final}

Si hemos dotado a este texto del formato de una Ley no es porque olvidemos que las normas pueden ser derogadas por abajo mediante múltiples fugas, desobediencias y tácticas cotidianas, sino como estrategia que pretende llamar la atención 
—aunque no esté de moda en un contexto en el que "salvar lo público" es el único combate posible - sobre la estructura de la intervención social y policial como tecnologías anudadas en pro del sostenimiento del orden social, - aún en sus variaciones progresistas a favor del Bienestar- En uno de sus últimos trabajos, acerca precisamente del gobierno neoliberal de la inseguridad social, Wacquant advertía en sus primeras páginas que:

[sus objetivos] obligan a exagerar el entramando con el riesgo de dar la impresión de que lo neoliberal es un principio totalizador que arrasa todo a su paso. Esta (sobre)simplificación es un momento inevitable en el análisis de un proceso en auge, cuyo coste bien vale la pena pagar si al menos se logra perfilar sus rasgos. El alto grado de coherencia es, por tanto, una consecuencia de la lente analítica utilizada (Wacquant, 2010: 23).

Con permiso del lector, hacemos nuestra esta advertencia. No es la ausencia de resistencias a las lógicas dominantes de lo que adolece la intervención sobre lo social, sino las condiciones axiomáticas de poder en las que ésta se inserta: su trabajo, más allá de las buenas intenciones, acaba por inscribirse del lado de lo que Jacques Rancière denomina policía - esto es, distribución jerárquica de las colectividades, los poderes y las funciones- más que del de la política - o emancipación que rompe con esa configuración, y que tiene como punto de partida la igualdad, y como punto de llegada su verificación-.

Madrid, Agosto de 2012 Mientras escribimos este artículo en la noche cálida de un parque de la periferia de Madrid, un coche de policía hace la ronda cada cinco minutos.

\section{Referencias bibliográficas}

ÁVILA, Débora y MALO, Marta

2010 "Manos invisibles. De la lógica neoliberal de lo social". Trabajo Social Hoy, 59: 137-171 . Madrid: Colegio Oficial de Diplomados en Trabajo Social de Madrid.

BARATTA, Alessandro

2001 “Seguridad”. Capitulo Criminológico, 29 (2): 1-24.

BONELLI, Laurent

2005 "Obsesión securitaria e ilegalismos populares en Francia, desde principios de 1980”, en R. Bergalli, I. Rivera Beiras (Coords.), Política criminal de la guerra. Barcelona: Anthropos, 99-143.

CASTEL, Robert

1986 "De la peligrosidad al riesgo“, en VV.AA., Materiales de Sociología Crítica. Madrid: La Piqueta, 219-243. 
COLECTIVO IOÉ

1995 "Despolitización de la cuestión social. Reflexiones en torno a la marginación". Estudios Sociológicos, 12: 203-216.

FASSIN, Didier

2011 La force de l'ordre. Une anthropologie de la police des quartiers. Paris: Seuil.

FOUCAULT, Michel

2006 Seguridad, Territorio, Población. México DF: FCE.

2008 Nacimiento de la biopolítica. México DF: FCE.

GARNIER, Jean-Pierre

2006 Contra los territorios del poder. Por un espacio público de debates y... de combates. Bilbao: Virus.

HERNANDO, Felipe

2008 "La seguridad en las ciudades: el nuevo enfoque de la geoprevención". Scripta Nova, XII, 270 (14).

OBSERVATORIO METROPOLITANO

2007 Madrid ¿La suma de todos? Globalización, Territorio, Desigualdad. Madrid: Traficantes de Sueños.

PAVARINI, Massimo

2006 "Políticas de seguridad y conflictos metropolitanos. Algunas reflexiones críticas sobre la experiencia italiana (vivida de cerca e intensamente)", en R. Bergalli, I. Rivera Beiras (Coords.), Emergencias urbanas. Barcelona: Anthropos, 109-132.

RANCIÈRE, Jacques

1996 "La distorsión: política y policía" en J. Rancière, El desacuerdo. Política y filosofía. Buenos Aires: Nueva Visión, 35-60.

2010 "El racismo, una pasión que viene de arriba", disponible en http://lapreneusedetemps.blogspot.com/2010/09/liberte-de-circulation.html

WACQUANT, Loïc

2010 Castigar a los pobres. El gobierno neoliberal de la inseguridad social. Barcelona: Gedisa.

ZIBECHI, Raúl

2011 Política \& Miseria. La relación entre el modelo extractivo, los planes sociales y los gobiernos progresistas. Buenos Aires: La Vaca Editora. 